\title{
Simultaneous Measurements by Advanced SAR and Radar Altimeter on Potential Improvement of Ocean Wave Model Assimilation
}

\author{
Xiao-Ming Li, Susanne Lehner, Member, IEEE, and Thomas Bruns
}

\begin{abstract}
Simultaneous measurements of significant wave height (SWH) obtained from two independent active microwave sensors of Radar Altimeter 2 (RA-2) and Advanced Synthetic Aperture Radar (ASAR) onboard the ENVIronmental SATellite (ENVISAT) are used for a global verification of ocean wave models (WAMs). In the present study, SWH is retrieved from ASAR wave mode data using the empirical algorithm called C-band WAVE algorithm for ENVISAT, which is capable of representing total SWH irrespective of the cutoff of SAR. Comparisons of two radar measurements with the reanalyses ERA-Interim model (with assimilation of RA-2 measurements) and the German operational WAM (Deutscher Wetterdienst Global Sea wave Model, without assimilation before 2008) show that both WAMs agree well with ASAR and RA-2 measurements. However, the discrepancies of agreement indicate to which extent that the assimilation of RA-2 measurements can improve the performance of WAMs. Moreover, differences in the comparisons of ASAR and RA-2 measurements with the same WAM of ERAInterim reveal that, although assimilation of RA-2 significantly improves the accuracy of model on grids near the RA-2 tracks, the improvement decreases along with the increase of distance between model grids and RA-2 tracks.
\end{abstract}

Index Terms-Radar Altimeter (RA), sea surface wave, synthetic aperture radar (SAR), wave modeling.

\section{NOMENCLATURE}

$\begin{array}{ll}\text { ASAR } & \text { Advanced Synthetic Aperture Radar. } \\ \text { CWAVE_ENV } & \text { C-band WAVE algorithm for ENVISAT. } \\ \text { DWD } & \text { Deutscher Wetterdienst. } \\ \text { ECMWF } & \text { European Centre for Medium-Range Weather } \\ & \text { Forecasts. } \\ \text { ENVISAT } & \text { ENVIronmental SATellite. } \\ \text { ERA } & \text { ECMWF reanalysis. }\end{array}$

Manuscript received January 17, 2013; revised March 27, 2013 and April 29, 2013; accepted May 1, 2013. This work was supported in part by the German Federal Ministry of Transport, Building and Urban Development (BMVBS) project "Seegangsmonitor" under Grant 97.0304-2012 and in part by the German Federal Ministry of Education and Research (BMBF) project "MaMo" under Grant 03G0733A.

X.-M. Li and S. Lehner are with Remote Sensing Technology Institute, German Aerospace Center (DLR), 82234 Wessling, Germany (e-mail: Xiao. Li@dlr.de; Susanne.Lehner@dlr.de).

T. Bruns is with Seeschifffahrtsberatung, Deutscher Wetterdienst (German Weather Service), 20359 Hamburg, Germany (e-mail: Thomas.Bruns@ dwd.de).

Color versions of one or more of the figures in this paper are available online at http://ieeexplore.ieee.org.

Digital Object Identifier 10.1109/TGRS.2013.2262137

\author{
ERA-Interim \\ ERS \\ GDR \\ GSM \\ NDBC \\ RA \\ RA-2 \\ SAR \\ SWH \\ VV \\ WAM \\ WVW \\ ERA from January 1979 onward. \\ European Remote Sensing. \\ Geophysical Data Record. \\ Global Sea wave Model. \\ National Data Buoy Center. \\ Radar Altimeter. \\ RA 2 onboard ENVISAT. \\ Synthetic Aperture Radar. \\ Significant wave height. \\ Vertical-vertical. \\ Wave model. \\ ASAR wave mode Level 2 product of wave \\ spectra.
}

\section{INTRODUCTION}

B EFORE it ran out of operation in April 2012, ENVISAT ${ }^{1}$ has provided an invaluable data set on monitoring land, ocean, and atmosphere for over ten years. The active microwave sensor of ASAR onboard ENVISAT operates at C-band to form images in different modes, among which image mode and wide swath mode data are widely used for land surface and coastal monitoring due to large area coverage (with swath widths of 100 and $400 \mathrm{~km}$, respectively) and high spatial resolution. In addition, ASAR can operate in wave mode to provide a small image (often called "imagette") every $100 \mathrm{~km}$ along track with a ground coverage of $\sim 5 \mathrm{~km} \times 10 \mathrm{~km}$. Despite its limited spatial coverage, the wave mode has the advantage of collecting imagettes automatically on a global scale.

Usefulness of spaceborne SAR data for surface wave measurements has been discussed and studied since the launch of SEASAT in 1979. SAR is still the only instrument that can provide 2-D surface wave information from space. Hasselmann et al. [1] give a detailed overview of the development of SAR/ocean wave retrieval theories and methodologies. The conventional approaches to retrieve full 2-D wave spectra from SAR data are generally based on a nonlinear inversion scheme [2], [3], which needs a priori spectra taken from a numerical WAM. Without prior information, only waves imaged within the SAR-inherent cutoff wavenumber domain can be retrieved. Therefore, the ASAR wave mode Level 2 product WVW [4] represents only the low-frequency part of wave spectra, i.e., the swell wave spectra. The ASAR wave mode WVW

\footnotetext{
${ }^{1}$ All acronyms used in this paper are listed in the Nomenclature section.
} 


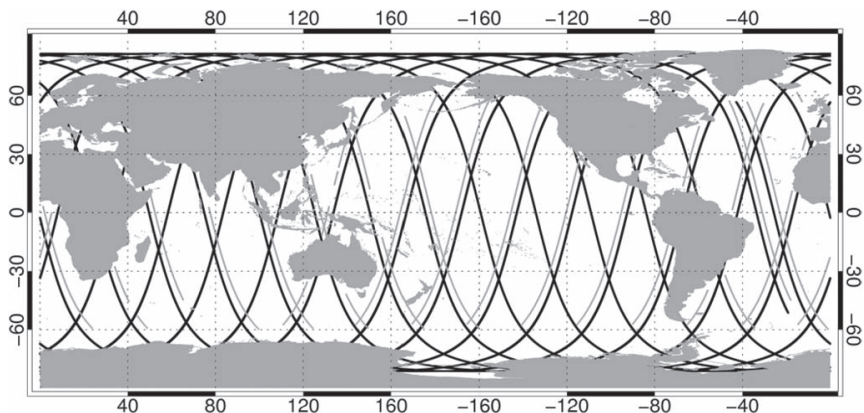

Fig. 1. Illustration of double tracks of (gray) the ASAR (limited between $65^{\circ} \mathrm{S}$ and $65^{\circ} \mathrm{N}$ ) and (black) the RA-2 scanning sea surface simultaneously in one day.

product is used, e.g., for WAM validation and comparison [5], [6], assimilation [7], monitoring of swell propagation over ocean basins, and estimation of ocean swell dissipation [8], [9].

Alternatively, empirical algorithms presented in [10] and [11] enable to derive characteristic wave parameters such as SWH and mean wave period directly from SAR wave mode data, without a priori information. The empirical algorithm CWAVE_ENV [11] is specialized on processing the ENVISAT ASAR wave mode data. Validation based on a two-month data set shows that the retrieved SWH is in a close agreement with in situ buoy measurements with a bias of $0.06 \mathrm{~m}$ in deep water [11].

Spaceborne RA is an instrument that can provide measurements of wave height. The accuracy of SWH derived from altimetry data is about $\pm 10 \%$ or $0.25 \mathrm{~m}$, e.g., presented in [12]-[14]. RA measurements are used for studies of wave climate [15]-[17], numerical WAM assimilation [18]-[20], and validation [21], [22].

ENVISAT also carries a RA, which is called RA-2. The nadir-looking instrument $\mathrm{RA}-2$ receives reflected echo from the sea surface, while the right-looking ASAR onboard ENVISAT simultaneously obtains 2-D sea surface backscatter to be processed to images. The ground distance between RA-2 and ASAR tracks is around $335 \mathrm{~km}$, when ASAR operates at wave mode with an incidence angle of $23^{\circ}$. Fig. 1 illustrates ASAR (gray) and RA-2 (black) that scan the sea surface in double tracks during one day. One can find that simultaneous operations of the two radars onboard ENVISAT provide a unique opportunity to measure sea state at the same time but at different locations. In particular, in connection with CWAVE_ENV algorithm, ASAR can be treated as an independent sensor complement to RA-2 to measure wave height. The present study, therefore, demonstrates the usefulness of the simultaneous measurements of ASAR and RA-2 data for studying on verification and on potential improvement of global WAM.

The structure of this paper is as follows. Section II describes the data set used in this study. This is followed by a further validation of SWH derived from long-term ASAR wave mode data against buoy measurements in Section III. In Section IV, simultaneous wave measurements by ASAR and RA-2 are used for verifications of the two numerical WAMs. This paper closes with discussion and conclusions in Section V.

\section{DATA SET DESCRIPTION}

The satellite and numerical WAM data represent different temporal and spatial scales. Both ASAR and RA-2 are instantaneous measurements with footprint sizes of several kilometers. Numerical WAM data are available at synoptic times and represent average sea state conditions in grid boxes. Thus, in addition to a brief description of the data set used in this study, we explain how these data sets are processed and collocated to make them compatible for comparisons.

\section{A. ASAR Wave Mode Data}

The ASAR wave mode data acquired at VV polarization and incidence angle of approximately $23^{\circ}$ are processed using the CWAVE_ENV algorithm. As the sea surface is imaged two-dimensionally by SAR, not only the sea surface wave information but also other features, such as sea ice, rain cells, and slicks, may be contained in SAR wave mode data [23]. Therefore, a homogeneity test [24] is applied to exclude data which contain features that are not related to sea surface waves. Finally, $90 \%$ of the ASAR imagettes pass the quality control and are used for deriving SWH.

\section{B. RA-2 Data}

The RA-2 GDR product accessed from the CERSAT portal (ftp://ftp.ifremer.fr/ifremer/cersat/products/swath/altimeters/) includes SWH derived from measurements in Ku-band. Erroneous measurements in this data set are marked by quality flags. An additional along-track running window with a size of $100 \mathrm{~km}$ has been applied to remove few spurious SWH measurements [25] in the accessed data set. Further correction as given in (1) is made using in situ buoy measurements [26]

$$
\mathrm{SWH}_{\mathrm{cor}}= \begin{cases}1.0095 * \mathrm{SWH}+0.0192, & \mathrm{SWH}>3.41 \mathrm{~m} \\ 0.4358+0.5693 * \mathrm{SWH}+0.1650 & \\ * \mathrm{SWH}^{2}-0.0210 * \mathrm{SWH}^{3}, & \mathrm{SWH} \leq 3.41 \mathrm{~m} .\end{cases}
$$

\section{GSM WAM Data}

The GSM WAM operated routinely at the DWD is based on the third-generation WAM [27] cycle 4 [28] using a wind forcing from the global atmospheric forecast model Global Model on a nearly uniform 40-km grid. The GSM WAM has a spatial resolution of $0.75^{\circ} \times 0.75^{\circ}$ and is available at synoptic times of every $3 \mathrm{~h}$. Until February 2008, the model was run without assimilation of wave observations of RA. Accordingly, the forecast integration always starts with a sea state predicted $12 \mathrm{~h}$ before by the previous model run. Therefore, only wave fields at forecast times $T+3$ to $T+12$ are used in the present study.

\section{ECMWF ERA-Interim WAM Data}

ERA-Interim is the latest global reanalysis model produced by the ECMWF, which covers the period from January 1, 1979, onward, and continues to be extended forward in near real time [29]. The reanalysis ERA-Interim WAM is also based on the 
third-generation WAM, with several enhancements in physics and numerics [30]. The introduction of a scheme in the ERAInterim WAM for treating unresolved bathymetry effects and a reformulation of the dissipation source term [31] is considered to be a significant contribution for climate applications [29].

The sea surface wind field measured by the scatterometers onboard ERS-1/2 and QuikSCAT is assimilated in the reanalyzed wind field forcing the WAM. Surface wave measurements from spaceborne RAs onboard ERS-1/2, ENVISAT, and JASON-1/2 are assimilated in the ERA-Interim WAM as well using a sequential method introduced in [18].

The ERA-Interim WAM has a spatial resolution of $0.75^{\circ} \times$ $0.75^{\circ}$, and it is available at synoptic times of every $6 \mathrm{~h}$.

\section{E. In Situ Buoy Data}

In situ measurements of SWH are accessed from the NDBC, USA, and Environment Canada buoy networks. Buoy measurements consisting of 20-min records are available hourly. In this paper, buoy measurements are used to verify the quality of SWH derived from ASAR wave mode data by CWAVE_ENV algorithm.

\section{F. Data Collocation}

The ASAR wave mode data are collocated with buoy measurements using a temporal lag of $30 \mathrm{~min}$. Buoys are generally moored in coastal regions. However, the ASAR wave mode data are often acquired over open ocean. Therefore, a rather large spatial window with a size of $100 \mathrm{~km}$ is chosen for collocating ASAR imagettes with buoy measurements.

The footprint of RA-2 is nominally $2-10 \mathrm{~km}$ in diameter, depending on sea state, which is sufficiently large and comparable with coverage of ASAR wave mode data. Therefore, measurements of RA-2 at locations nearest to ASAR wave mode data are collocated. This ensures that the SWH derived from both observations is based on a comparable spatial coverage. On the other hand, RA-2 acquires one measurement at 1-s sample rate along track; thus, two consecutive points are separated by $6-7 \mathrm{~km}$. However, two consecutive ASAR wave mode data are separated by approximately $100 \mathrm{~km}$. Therefore, RA-2 measurements within a circle with center at the ASAR location and a radius of $335 \mathrm{~km}$ (ground distance between the two tracks) are grouped. The averaged SWH and locations are considered to be the collocated RA-2 measurements with ASAR. The maximum number of RA-2 samples within a circle is limited to 15 , which corresponds to a ground distance of around $100 \mathrm{~km}$ that is equal to the sampling distance of ASAR wave mode data. In fact, this process behaves like a smoothing window along RA-2 track. Note that the great circle distance between footprints of RA-2 and ASAR is calculated for the nearest and averaged collocations.

Both WAM data have a spatial resolution of $0.75^{\circ} \times 0.75^{\circ}$. Thus, satellite measurements are allocated to model results at the nearest grid box using a threshold of $0.75^{\circ} / 2$. The ASAR and RA-2 measurements are collocated to WAM results at respective grid boxes, due to a large ground distance between their tracks.
Temporal resolution of the ERA-Interim WAM is half of that of the GSM WAM. For consistency reasons, its temporal resolution is increased from 6 to $3 \mathrm{~h}$ by a linear interpolation. Consequently, a threshold of $1.5 \mathrm{~h}$ is used for temporal collocation of satellite and model data.

\section{VERIFICATION OF ASAR-RETRIEVED SWH}

The empirical algorithm CWAVE_ENV is designed to derive fully integral wave parameters from ASAR wave mode data [11], which follows the development of CWAVE algorithm for ERS-2/SAR wave mode data [10]. A previous validation of SWH retrieved by CWAVE_ENV algorithm using a twomonth (January and February 2007) ASAR wave mode data set is presented in [11]. To further verify the quality of retrieved SWH, a comparison against buoy measurements using a 17-month data set in time period of January 2006 to May 2007 is conducted. Prior to presenting the validation, a brief description of CWAVE_ENV algorithm is given hereinafter.

\section{A. Brief Description of the CWAVE_ENV Algorithm}

The equation used in the CWAVE_ENV algorithm takes the following form proposed in [10]:

$$
W=a_{0}+\sum_{1 \leq i \leq n_{s}} a_{i} s_{i}+\sum_{1 \leq i \leq j \leq n_{s}} a_{i, j} s_{i} s_{j}
$$

where $W$ represents the integral wave parameters to be derived from ASAR wave mode data, such as SWH and mean wave period. In the present study, the parameter of SWH is used, which is defined as

$$
\mathrm{SWH}=4 \sqrt{\int E(f, \theta) d f d \theta}
$$

where $E(f, \theta)$ is the 2-D frequency-direction wave spectrum.

In (2), the integral parameter of surface waves is expressed as a quadratic formulation consisting of 22 parameters $\mathbf{S}\left(s_{1}, \ldots\right.$, $s_{n_{s}}$ ) derived from ASAR wave mode data. The nonlinearities and a possible coupling between these parameters are taken into account in the equation by adding quadratic terms of $s_{i} s_{j}$. Among the parameters, normalized radar cross section $\left(\sigma_{0}\right)$ and variance of the normalized intensity image (cvar) are calculated from the ASAR wave mode intensity image. The other 20 parameters are extracted from ASAR image variance spectrum using a set of orthonormal functions [21]. Corresponding to the linear and quadratic terms of ASAR parameters in (2), the dimension of coefficients in vector $\mathbf{A}\left(a_{0}, \ldots, a_{n s}\right.$, $\left.a_{11}, \ldots, a_{n_{s}} a_{n_{s}}\right)$ is $0.5\left(n_{s}+1\right)\left(n_{s}+2\right)$, i.e., 276 in the CWAVE_ENV algorithm, which is quite large, and therefore, they are not listed in this paper but are available on request from the authors. Although (2) does not explain the geophysical relation between SAR image parameters and characteristic wave parameters, it yields an empirical way to derive wave parameters from SAR data without the need of a priori information.

As ASAR wave mode data are quite often acquired over the open sea where in situ measurements are scarce, the present coefficients of the CWAVE_ENV model are determined using more than 23000 data pairs of ASAR wave mode data 
TABLE I

Statistical Parameters of the CWAVE_ENV Model Validation BY COMPARING THE ASAR-DERIVED SWH TO IN SiTU BUOY (DEEP WATER) MEAsurements AND Crossover RA MEAsurements

\begin{tabular}{cccc}
\hline \hline & ASAR vs. Buoy & $\begin{array}{c}\text { ASAR vs. } \\
\text { JASON }\end{array}$ & ASAR vs. GFO \\
\hline $\begin{array}{c}\text { Correlation } \\
\text { Bias (m) }\end{array}$ & 0.90 & 0.94 & 0.92 \\
$\begin{array}{c}\text { (ASAR-Other) } \\
\text { RMSE (m) }\end{array}$ & 0.06 & -0.13 & -0.11 \\
Scatter Index & 0.70 & 0.46 & 0.53 \\
\hline \hline
\end{tabular}

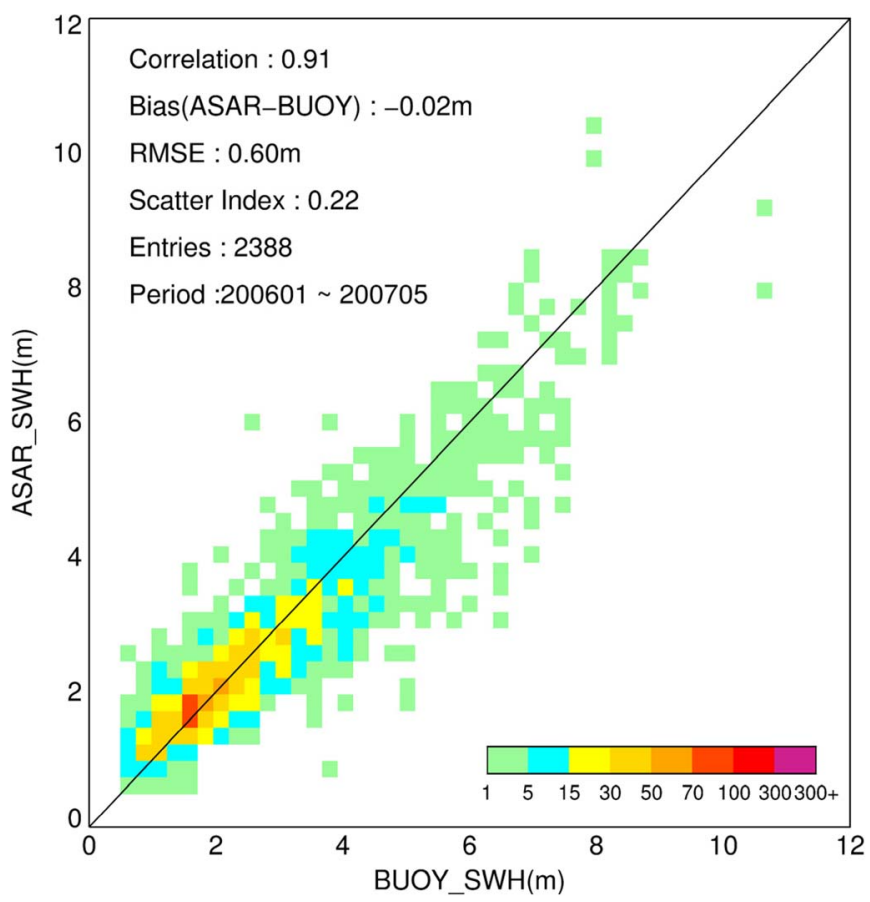

Fig. 2. Comparison of ASAR SWH with buoy measurements for collocation distance less than $100 \mathrm{~km}$.

and the collocated ECMWF operational WAM (the thirdgeneration WAM) with a spatial resolution of $0.5^{\circ} \times 0.5^{\circ}$. The 2-D model wave spectra with 25 frequencies and 12 directions are provided, which assimilate RA and SAR measurements (S. Abdalla, personal communication). The available ASAR wave mode data since 2002 are being processed to collocate with in situ buoy measurements for retuning of the CWAVE_ ENV algorithm.

\section{B. ASAR SWH Against Buoy Measurements}

Statistical parameters achieved in the previous validation of CWAVE_ENV algorithm [11] are briefly summarized in Table I for reference. A further validation using a data set acquired between January 2006 and May in 2007 is shown in Fig. 2. The color-coded squares in the figure indicate the amount of data pairs in a step size of $0.25 \mathrm{~m}$ of SWH measured by buoys. The comparison shows a close agreement between ASAR-retrieved SWH and buoy measurements with a bias of $-0.02 \mathrm{~m}$, an rmse of $0.60 \mathrm{~m}$, and a Scatter Index (SI) of $22 \%$.

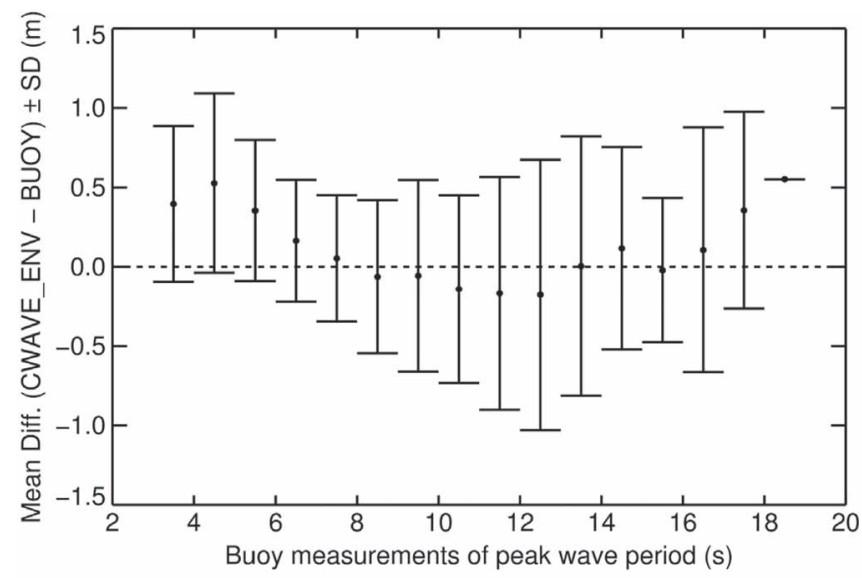

(a)

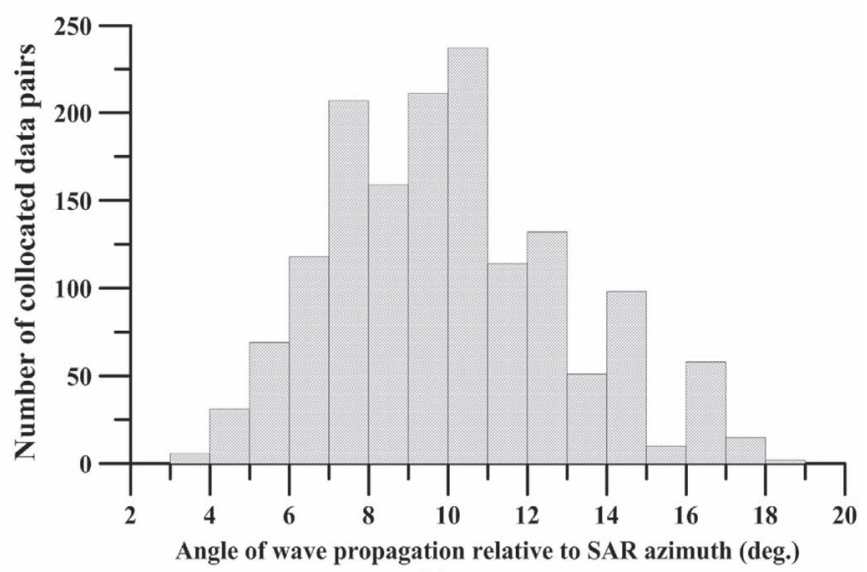

(b)

Fig. 3. (a) Mean bias between ASAR and buoy SWH as a function of buoy measurements of peak wave period. Step size of $1 \mathrm{~s}$ is used to group the ASAR and buoy collocations. The error bars show the standard deviation of mean bias. (b) Histogram of collocated data pairs for deriving the bias in (a).

It is often discussed that information in SAR measurements may be lost for surface waves traveling in azimuth direction or for short waves, i.e., the so-called cutoff effect, which, in turn, makes the retrieved wave parameters inaccurate. Therefore, we use collocations of buoys with measurements of peak wave period (1821 cases) and peak wave direction (280 cases) to verify the dependence of retrieved SWH by CWAVE_ENV algorithm on the SAR cutoff.

Bias of SWH as a function of buoy peak wave period is shown in Fig. 3(a). The retrieved SWH agrees well with buoy measurements under either wind sea or swell conditions. The best agreement with difference less than $0.20 \mathrm{~m}$ is achieved for peak wave period in the range of 7-16 s, which corresponds to a peak wavelength of $76-400 \mathrm{~m}$ in deep water. For the period between 3 and $6 \mathrm{~s}$, which corresponds to a peak wavelength of 16-56 m, the CWAVE_ENV algorithm yields slightly higher SWH than measurements. Comparing Fig. 3(a) and (b), one may notice that variation of bias tends to be also related to the number of collocations. As there are no significant fluctuations of bias between retrieved ASAR SWH and buoy measurements along with peak wave period, we therefore conclude that the quality of retrieved SWH has no significant dependence on peak wave period. 


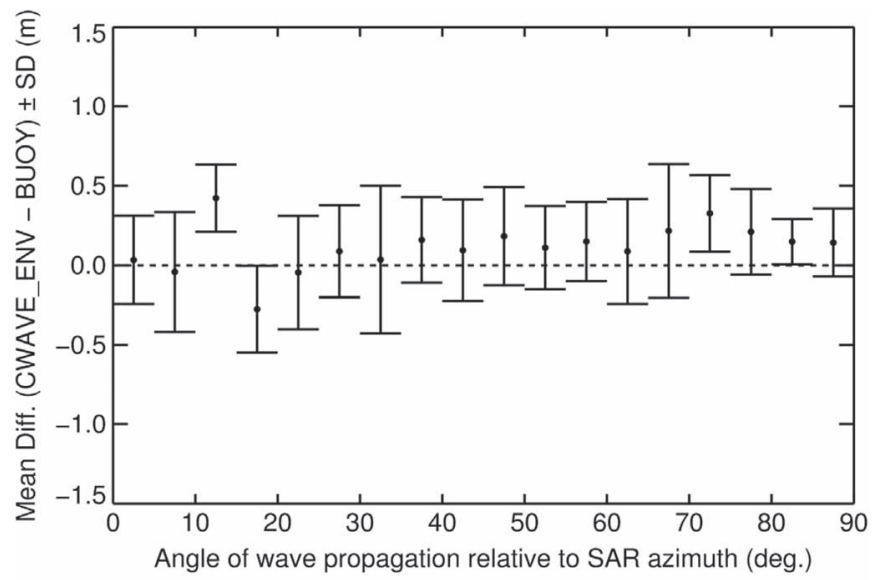

(a)

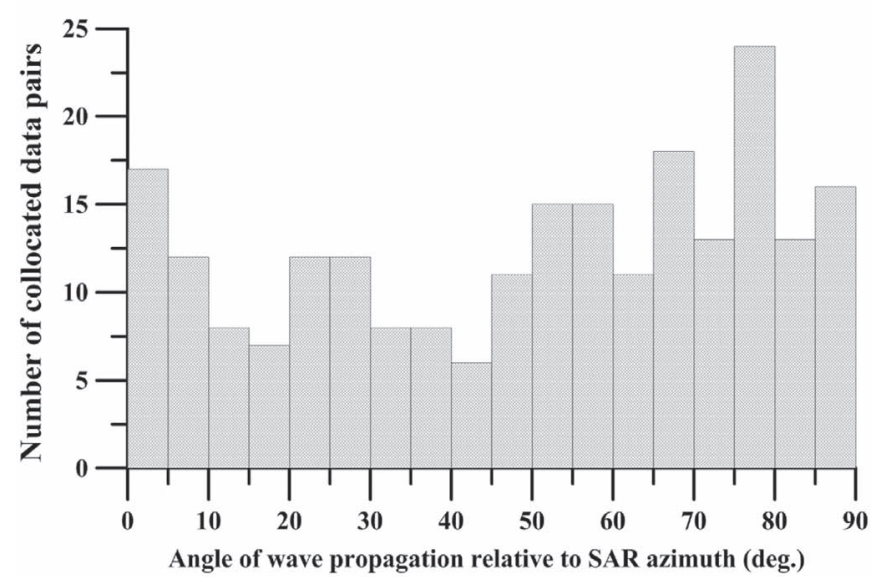

(b)

Fig. 4. Same as Fig. 3, but for the bias as a function of peak wave direction relative to the ASAR azimuth angle.

Fig. 4(a) shows the bias of SWH as a function of the angle between peak wave directions relative to the ASAR azimuth direction. The mean difference is rather stable and varies between -0.25 and $0.25 \mathrm{~m}$ except for relative angles between $10^{\circ}$ and $20^{\circ}$, which may be attributed to the limited data pairs (less than ten), as shown in Fig. 4(b). Nevertheless, this comparison indicates that differences for SWH between the ASAR retrieval using CWAVE_ENV and buoy measurements have no significant dependence on wave propagation direction.

The presented two validation exercises indicate that the CWAVE_ENV algorithm yields reliable SWH estimation without being affected by the SAR cutoff. In other words, the SWH retrieved by CWAVE_ENV depicts the energy of long waves and the waves beyond the cutoff as well, although short waves are not directly imaged by ASAR.

\section{COMPARISON OF RADAR MEASUREMEnTS OF SWH With NUMERICAL WAMS}

In this section, ASAR and RA-2 measurements of SWH are compared with the results of the GSM and ERA-Interim WAMs for the time period between June 2006 and May 2007.

An example of simultaneous wave observations by ASAR and RA-2 in high sea state over the North Atlantic on January 19, 2007, is shown in Fig. 5. From this example, we can find at

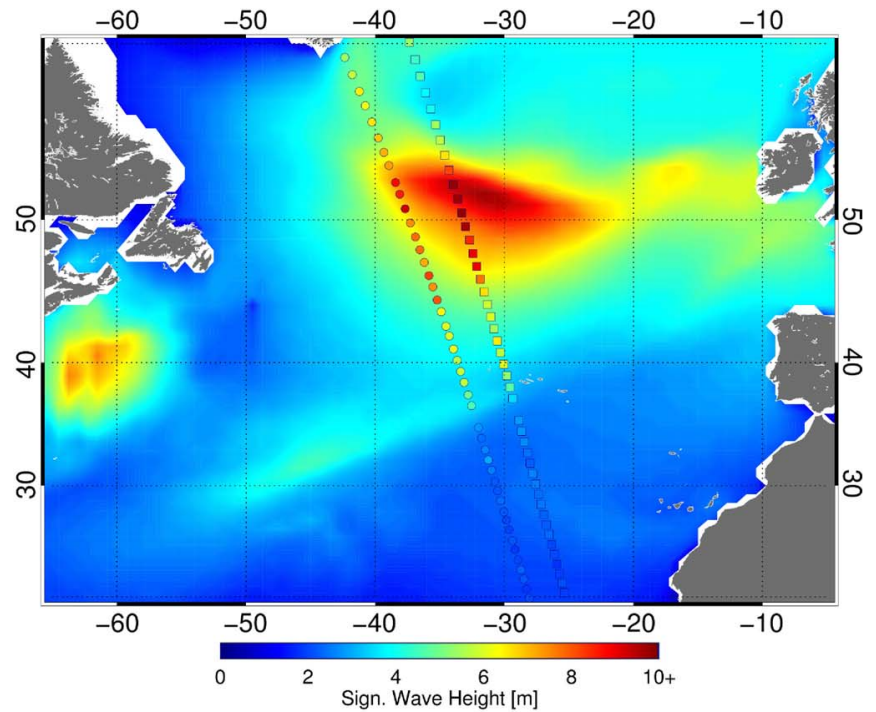

(a)

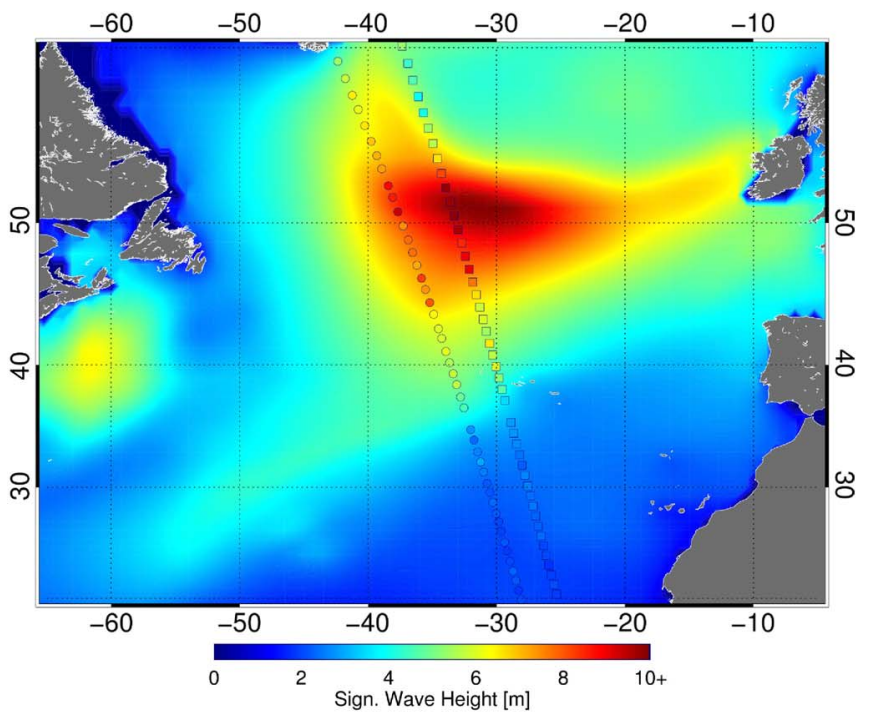

(b)

Fig. 5. Examples of simultaneous SWH observations by ASAR and RA-2 under high sea state in comparison with underlying WAMs of the (a) GSM and (b) ERA-Interim at 0:00 UTC on January 20, 2007. The color-coded squares and circles indicate SWHs derived from ASAR and RA-2, respectively. The satellite data are acquired between 23:39 and 23:51 UTC on January 19, 2007.

least two interesting points. First, the correspondence between ERA-Interim WAM and observations along the RA-2 track (circle) reveals the fact that RA-2 measurements are assimilated in the model. The correspondence is relatively poor in the case of GSM, which was operated without assimilation. Second, ERA-Interim wave height is less improved along the ASAR track (squares). Therefore, this example demonstrates, on one hand, that the simultaneous measurements can verify to what extent that SWH is improved due to assimilation. On the other hand, two measurements have potential to be used jointly for data assimilation into numerical WAMs.

\section{A. Annual Comparison}

Annual comparison of radar measurements with numerical WAM results of SWH over the global oceans is presented in the following. 
This article has been accepted for inclusion in a future issue of this journal. Content is final as presented, with the exception of pagination.

TABLE II

STATISTICAL PARAMETERS OF COMPARISONS With THE GSM WAM FOR SWH OVER THE GLOBE BASINS, THE NH, THE SH, AND THE TR IN ONE-YEAR PERIOD

\begin{tabular}{|c|c|c|c|c|c|}
\hline & $\begin{array}{c}\text { Mean } \\
\text { forecast (m) }\end{array}$ & $\begin{array}{c}\text { Mean } \\
\text { observations } \\
(\mathrm{m}) \\
\end{array}$ & $\begin{array}{l}\text { Bias } \\
(\mathrm{m})\end{array}$ & $\begin{array}{c}\text { RMSE } \\
\text { (m) }\end{array}$ & SI \\
\hline \multicolumn{6}{|c|}{ Global basins } \\
\hline $\begin{array}{c}\text { ASAR } \\
\text { vs.GSM }\end{array}$ & 2.67 & 2.71 & 0.04 & 0.51 & $19.1 \%$ \\
\hline $\begin{array}{l}\text { RA-2_near } \\
\text { vs. GSM } \\
\text { RA- }\end{array}$ & 2.67 & 2.73 & 0.07 & 0.52 & $19.2 \%$ \\
\hline $\begin{array}{l}2 \text { 2_mean } \\
\text { vs. GSM }\end{array}$ & 2.67 & 2.73 & 0.07 & 0.49 & $18.1 \%$ \\
\hline \multicolumn{6}{|c|}{ Northern Hemisphere $\left(20^{\circ} \mathrm{N} \sim 65^{\circ} \mathrm{N}\right)$} \\
\hline $\begin{array}{c}\text { ASAR } \\
\text { vs. GSM }\end{array}$ & 2.48 & 2.53 & 0.05 & 0.53 & $21.3 \%$ \\
\hline $\begin{array}{l}\text { RA-2_near } \\
\text { vs. GSM }\end{array}$ & 2.46 & 2.52 & 0.06 & 0.52 & $21.1 \%$ \\
\hline $\begin{array}{c}\text { RA- } \\
\text { 2_mean } \\
\text { vs. GSM }\end{array}$ & 2.46 & 2.52 & 0.06 & 0.49 & $19.8 \%$ \\
\hline \multicolumn{6}{|c|}{ Southern Hemisphere $\left(20^{\circ} S \sim 65^{\circ} S\right)$} \\
\hline $\begin{array}{c}\text { ASAR vs. } \\
\text { GSM }\end{array}$ & 3.21 & 3.31 & 0.10 & 0.60 & $18.4 \%$ \\
\hline $\begin{array}{l}\text { RA-2_near } \\
\text { vs. GSM } \\
\text { RA- }\end{array}$ & 3.23 & 3.47 & 0.24 & 0.61 & $17.4 \%$ \\
\hline $\begin{array}{l}\text { 2_mean } \\
\text { vs. GSM }\end{array}$ & 3.23 & 3.47 & 0.24 & 0.58 & $16.4 \%$ \\
\hline \multicolumn{6}{|c|}{ Tropics $\left(20^{\circ} \mathrm{S} \sim 20^{\circ} \mathrm{N}\right)$} \\
\hline $\begin{array}{l}\text { ASAR vs. } \\
\text { GSM }\end{array}$ & 2.16 & 2.13 & -0.03 & 0.38 & $17.5 \%$ \\
\hline $\begin{array}{l}\text { RA-2_near } \\
\text { vs. GSM } \\
\text { RA- }\end{array}$ & 2.15 & 2.04 & -0.11 & 0.39 & $17.0 \%$ \\
\hline $\begin{array}{c}\text { 2_mean } \\
\text { vs. GSM }\end{array}$ & 2.15 & 2.04 & -0.11 & 0.35 & $15.6 \%$ \\
\hline
\end{tabular}

The difference between the modeled SWH $\left(x_{i}\right)$ and the observations from ASAR or RA-2 $\left(y_{i}\right)$ is quantified in terms of bias $\overline{y_{i}}-\overline{x_{i}}$, rmse $=\sqrt{(1 / n) \sum\left(y_{i}-x_{i}\right)^{2}}$, and SI $=1 / \overline{y_{i}}$ $\sqrt{1 / n \sum\left[\left(y_{i}-\overline{y_{i}}\right)-\left(x_{i}-\overline{x_{i}}\right)\right]^{2}}$. In all equations, $n$ is the number of the collocated data pairs. Statistical parameters of comparisons with the GSM and ERA-Interim models over the Globe, the Northern Hemisphere $(\mathrm{NH})$, the Southern Hemisphere (SH), and the Tropics (TR) are summarized in Tables II and III, respectively.

The statistical parameters listed in Table II indicate that the two independent but simultaneous measurements of ASAR and RA-2 yield similar comparisons with the GSM WAM, particularly that the nearest RA-2 measurements collocated with ASAR are used for comparison. This is because footprint sizes of RA-2 and ASAR are comparable. Thus, the nearest collocation RA-2 represents the same spatial coverage as ASAR to measure sea state. The similar comparisons also indicate that accuracy of SWH retrieved from ASAR wave mode data by CWAVE_ENV algorithm is close to that of RA-2 measurements.

Over the global oceans, the GSM WAM agrees well with both ASAR and RA-2 measurements, with SI values of $19.1 \%$
TABLE III

SAME AS TABLE II BUT FOR COMPARISON WITH THE ERA-INTERIM WAM

\begin{tabular}{|c|c|c|c|c|c|}
\hline & $\begin{array}{c}\text { Mean } \\
\text { forecast } \\
(\mathrm{m})\end{array}$ & $\begin{array}{c}\text { Mean } \\
\text { observations } \\
(\mathrm{m}) \\
\end{array}$ & $\begin{array}{l}\text { Bias } \\
(\mathrm{m})\end{array}$ & $\begin{array}{c}\text { RMSE } \\
\text { (m) }\end{array}$ & SI \\
\hline \multicolumn{6}{|c|}{ Global } \\
\hline $\begin{array}{c}\text { ASAR } \\
\text { vs.ERA }\end{array}$ & 2.68 & 2.70 & 0.02 & 0.46 & $17.0 \%$ \\
\hline $\begin{array}{l}\text { RA-2_near } \\
\text { vs. ERA }\end{array}$ & 2.67 & 2.73 & 0.06 & 0.29 & $10.6 \%$ \\
\hline $\begin{array}{c}\text { RA- } \\
\text { 2_mean } \\
\text { vs. ERA }\end{array}$ & 2.67 & 2.73 & 0.06 & 0.23 & $8.5 \%$ \\
\hline \multicolumn{6}{|c|}{ Northern Hemisphere $\left(20^{\circ} \mathrm{N} \sim 65^{\circ} \mathrm{N}\right)$} \\
\hline $\begin{array}{c}\text { ASAR } \\
\text { vs. ERA }\end{array}$ & 2.48 & 2.53 & 0.05 & 0.47 & $18.7 \%$ \\
\hline $\begin{array}{l}\text { RA-2_near } \\
\text { vs. ERA }\end{array}$ & 2.45 & 2.51 & 0.06 & 0.31 & $12.5 \%$ \\
\hline $\begin{array}{c}\text { RA- } \\
\text { 2_mean } \\
\text { vs. ERA }\end{array}$ & 2.45 & 2.51 & 0.06 & 0.26 & $10.2 \%$ \\
\hline \multicolumn{6}{|c|}{ Southern Hemisphere $\left(20^{\circ} \mathrm{S} \sim 65^{\circ} \mathrm{S}\right)$} \\
\hline $\begin{array}{c}\text { ASAR } \\
\text { vs. ERA }\end{array}$ & 3.39 & 3.32 & -0.07 & 0.53 & $15.5 \%$ \\
\hline $\begin{array}{l}\text { RA-2_near } \\
\text { vs. ERA } \\
\text { RA- }\end{array}$ & 3.39 & 3.47 & 0.08 & 0.33 & $9.4 \%$ \\
\hline $\begin{array}{l}\text { 2_mean } \\
\text { vs. ERA }\end{array}$ & 3.39 & 3.47 & 0.08 & 0.27 & $7.6 \%$ \\
\hline \multicolumn{6}{|c|}{ Tropics $\left(20^{\circ} \mathrm{S} \sim 20^{\circ} \mathrm{N}\right)$} \\
\hline $\begin{array}{c}\text { ASAR } \\
\text { vs. ERA }\end{array}$ & 2.02 & 2.13 & 0.11 & 0.35 & $16.4 \%$ \\
\hline $\begin{array}{l}\text { RA-2_near } \\
\text { vs. ERA } \\
\text { RA- }\end{array}$ & 1.99 & 2.04 & 0.05 & 0.22 & $10.9 \%$ \\
\hline $\begin{array}{c}2 \text { mean } \\
\text { vs. ERA }\end{array}$ & 1.99 & 2.04 & 0.05 & 0.17 & $8.2 \%$ \\
\hline
\end{tabular}

and $19.2 \%$, identical rmse of $0.52 \mathrm{~m}$, and bias values of -0.04 and $-0.07 \mathrm{~m}$, respectively. The GSM WAM has a rather large underestimation in the SH with bias values of -0.10 and $-0.24 \mathrm{~m}$ for respective comparison with ASAR and RA-2. However, both comparisons with ASAR and RA-2 show that the model slightly overestimates sea state in the TR basin.

The reanalysis ERA-Interim WAM shows better agreements with both radar observations than the GSM WAM. However, differences between ASAR versus GSM and ASAR versus ERA-Interim are not as significant as that derived from the comparison with RA-2 measurements. On the global scale, the quality of models in terms of rmse (versus ASAR) differs only by $0.05 \mathrm{~m}$, i.e., $10 \%$ relative to the rmse of GSM versus ASAR. However, with respect to comparisons with RA-2 measurements, when the nearest collocation is used, the difference of rmse increases significantly to $0.23 \mathrm{~m}(\sim 44 \%)$. Similar with rmse, SI also decreases relatively by around $10 \%$ and $44 \%$ when two models are compared with ASAR and RA-2, respectively. The differences are even larger when the averaged RA-2 measurements are used for comparisons, by around 53\% in terms of both rmse and SI for global oceans.

The physical and numerical improvements in the ERAInterim WAM should have the same impact on all grids no 

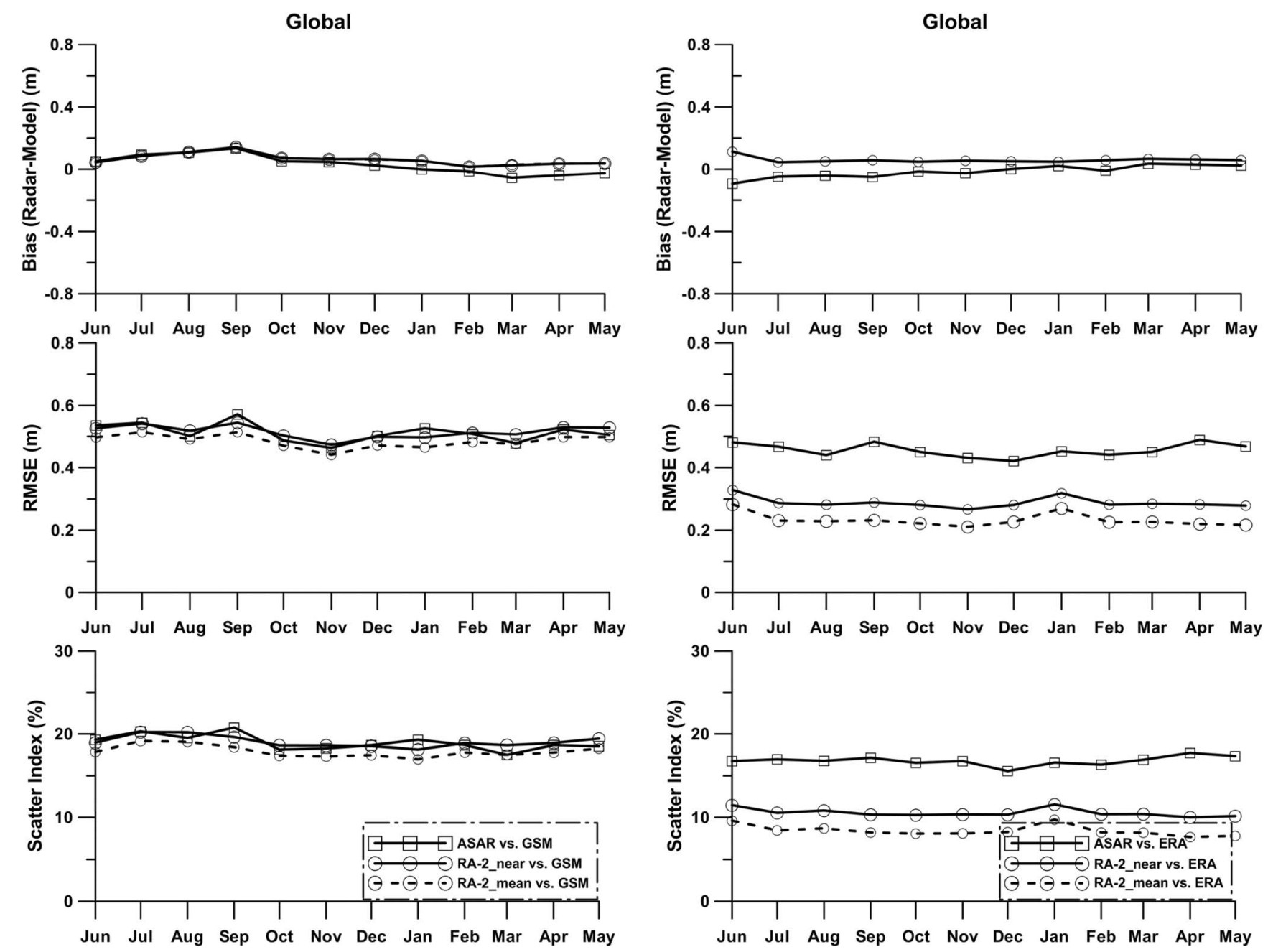

Fig. 6. Left plots are monthly comparisons of the GSM WAM with ASAR and RA-2 measurements of SWH over the global oceans. The right plots are the same as the left ones, but for comparison with the ERA-Interim WAM.

matter whether they are near to ASAR or RA-2 tracks. Comparison with the nonassimilated GSM WAM shows that the SWHs derived from ASAR and RA-2 are consistent. Thus, differences between the two comparisons of ERA-Interim with ASAR and RA-2 are considered to be mainly attributed to assimilation. In Table III, one can find that the difference between ASAR versus ERA-Interim and RA-2 versus ERA-Interim is around $37 \%$ for both rmse and SI over global oceans. If averaged RA-2 measurement is used for comparison, the differences increase to around $50 \%$. The difference of two radar measurements compared with the ERA-Interim model over different basins is also similar with that in global oceans. Therefore, we can preliminarily conclude that assimilation significantly improves accuracy of model results at grids near the RA-2 tracks, whereas improvement decreases by around $50 \%$ at model grids near the ASAR track.

\section{B. Monthly Comparison}

Monthly comparisons in the same period over the global oceans, NH, TR, and SH are shown in Figs. 6-9. The plots in the left panels in the four figures are comparisons with the
GSM WAM, and the right ones are comparisons with the ERAInterim WAM.

The same as annual comparison, the nearest and averaged collocations of RA-2 measurements are both presented for monthly comparison. There is no difference of bias between the nearest (solid lines with circles) and averaged (dashed lines with circles) RA-2 collocations that are used for comparisons. With respect to both rmse and SI, however, differences are consistent, around $6 \%$ and $16 \%$ for comparisons with the GSM and ERA-Interim WAMs, respectively. As WAMs represent averaged sea state within a grid box, it is reasonable that the averaged RA-2 measurements show better agreement with WAMs than the nearest RA-2 measurements.

Both verifications of the GSM and ERA-Interim WAMs in the $\mathrm{NH}$ and $\mathrm{SH}$ basins show apparent seasonal fluctuations in terms of rmse, while SI stays fairly constant throughout the year, particularly in the SH. However, in contrast to the GSM WAM which shows a seasonal variation of bias, the bias of ERA-Interim WAM has no apparent seasonal fluctuations.

Similar to the annual comparison, the monthly one also shows that the reanalysis ERA-Interim WAM is in better agreement with both radar measurements than the GSM WAM. On the other hand, although comparisons of ERA-Interim WAM 

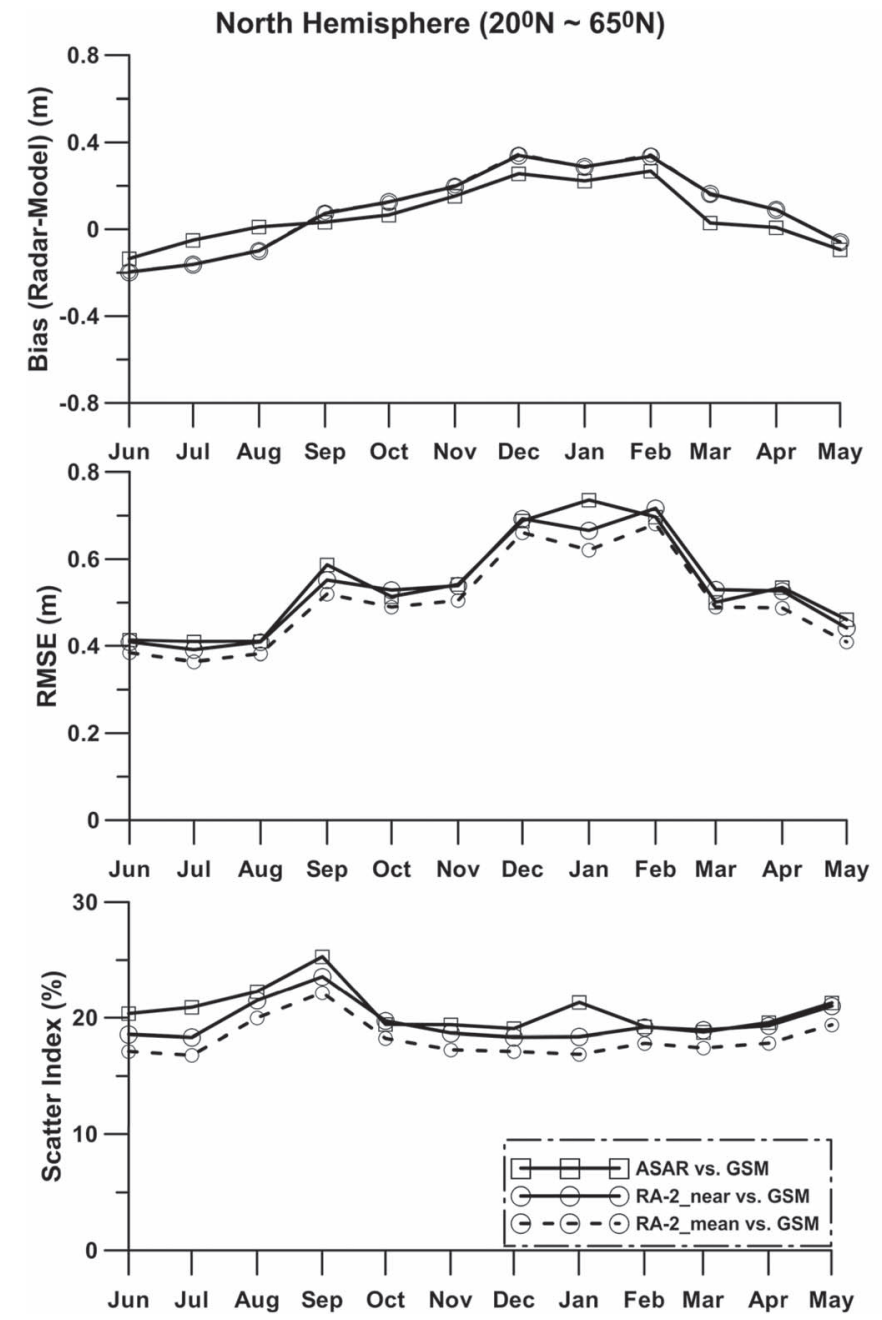

Fig. 7. Same as Fig. 6, but for comparisons in the NH.

with both radars show identical trends, statistical parameters of comparison with RA-2 are much smaller than those in comparison with ASAR measurements.

Both annual and monthly comparisons show that the ERAInterim WAM has a very good agreement with RA-2 measurements, which, as described previously, is attributed to the assimilation of RA-2 measurements. However, simultaneous measurement of RA-2 and ASAR reveals that the influence of the assimilation on the ERA-Interim WAM is "inhomogeneous" at different model grids. In the following, we attempt to explain this based on the widely used assimilation technique.

The optimal interpolation method, e.g., proposed by Lionello et al. [7], is widely implemented in numerical WAMs to assimilate satellite observations. The critical step of the assimilation scheme is to determine the weights $\left(G_{i}\right)$ to minimize the rmse of the analysis

$$
X^{a}=X^{p}+\sum_{i=1}^{N} G_{i}\left(X_{i}^{o}-\mathrm{H} X_{i}^{p}\right)
$$

where $X^{a}$ and $X^{p}$ represent the analyzed and the predicted (forecast) integral wave parameters (such as $\mathrm{SWH}$ ) at each model grid point, respectively. In order to determine the weights assigned to observations, the forecast and observations error

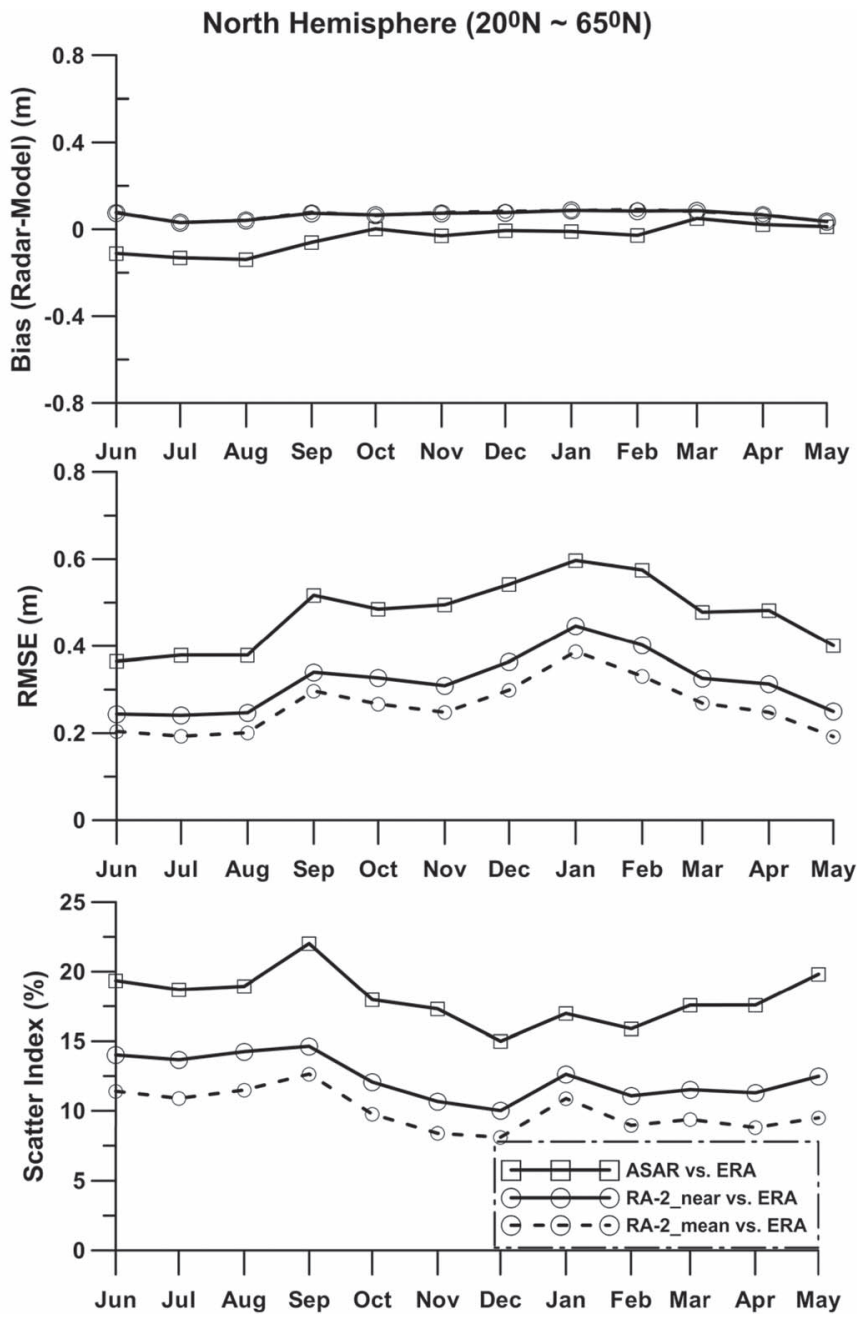

covariance matrices have to be known precisely. The observation errors are generally assumed to be spatially uncorrelated; however, the forecast error $P_{k j}$, on the other hand, is known to be horizontally correlated and is more difficult to specify. Generally, the correlation is exponentially decaying, such as that defined in the following equation by Lionello et al. [18]:

$$
P_{k j}=\exp \left[-\frac{\left|x_{k}-x_{j}\right|}{L}\right]
$$

where $L$ is the correlation length scale and $\left|x_{k}-x_{j}\right|$ is the distance between the points $k$ and $j$. In the assimilation approach conducted in the ECMWF, $300 \mathrm{~km}$ is used as the correlation length $L$ [32]. Equation (5) indicates that $P_{k j}$ decays exponentially along with the increase of distance. Therefore, the distance between RA-2 and ASAR tracks of around $335 \mathrm{~km}$ implies that the impact of RA-2 assimilation must have decayed considerably at grids near the ASAR track.

The spatially averaged SWH of RA-2 within each grid of model, which is also called "super observation," e.g., in [33], is generally used for assimilation, which explains why the averaged collocations of RA-2 show better agreement with the ERA-Interim WAM than the nearest collocations that are used, as shown in Table II and Figs. 6-9. 


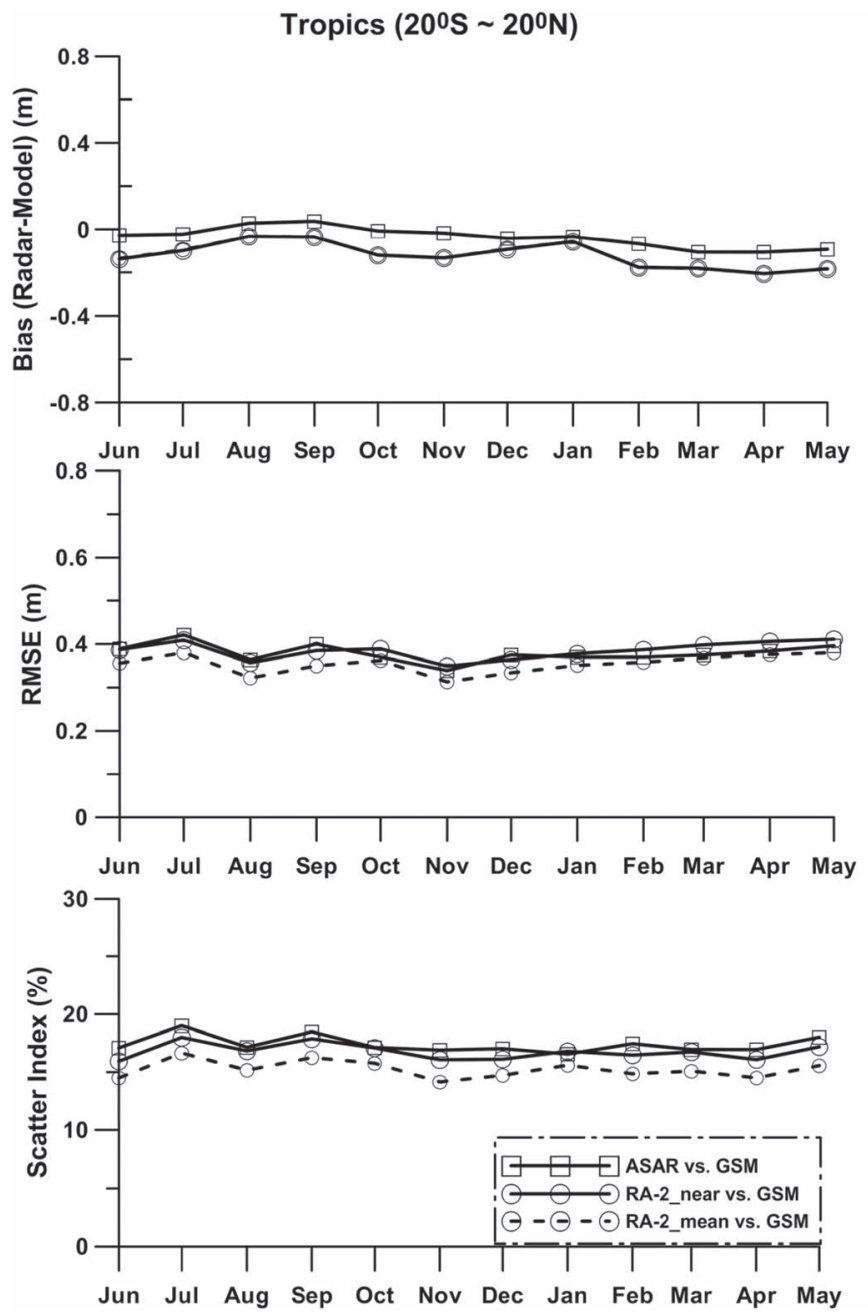

Fig. 8. Same as Fig. 6, but for comparisons in the TR.

\section{CONCLUSION AND OUTLOOK}

In the present study, simultaneous measurements of ASAR and RA-2 have been used for verification of two global WAMs using one-year data set to demonstrate potential on improvement of assimilations. The main conclusions are the following.

1) Although the CWAVE_ENV algorithm cannot yield full 2-D wave spectra from SAR data, the comparison with in situ buoy measurements shows that total SWH can be retrieved by this algorithm in good quality without needing a priori information from WAMs. Moreover, the mean bias between ASAR SWH and buoy measurements as a function of peak wave period and direction shows that the retrieved SWH is independent of the SAR cutoff. This remarkable result may change the view prominent for many years that the first guess from WAM is needed in order to derive the full integral wave parameters from SAR data.

2) Both the nearest and averaged RA-2 measurements collocated with ASAR wave mode data are used for comparisons with numerical WAMs. Statistical parameters in comparisons of GSM WAM with ASAR and RA-2 measurements are similar, particularly in terms of the

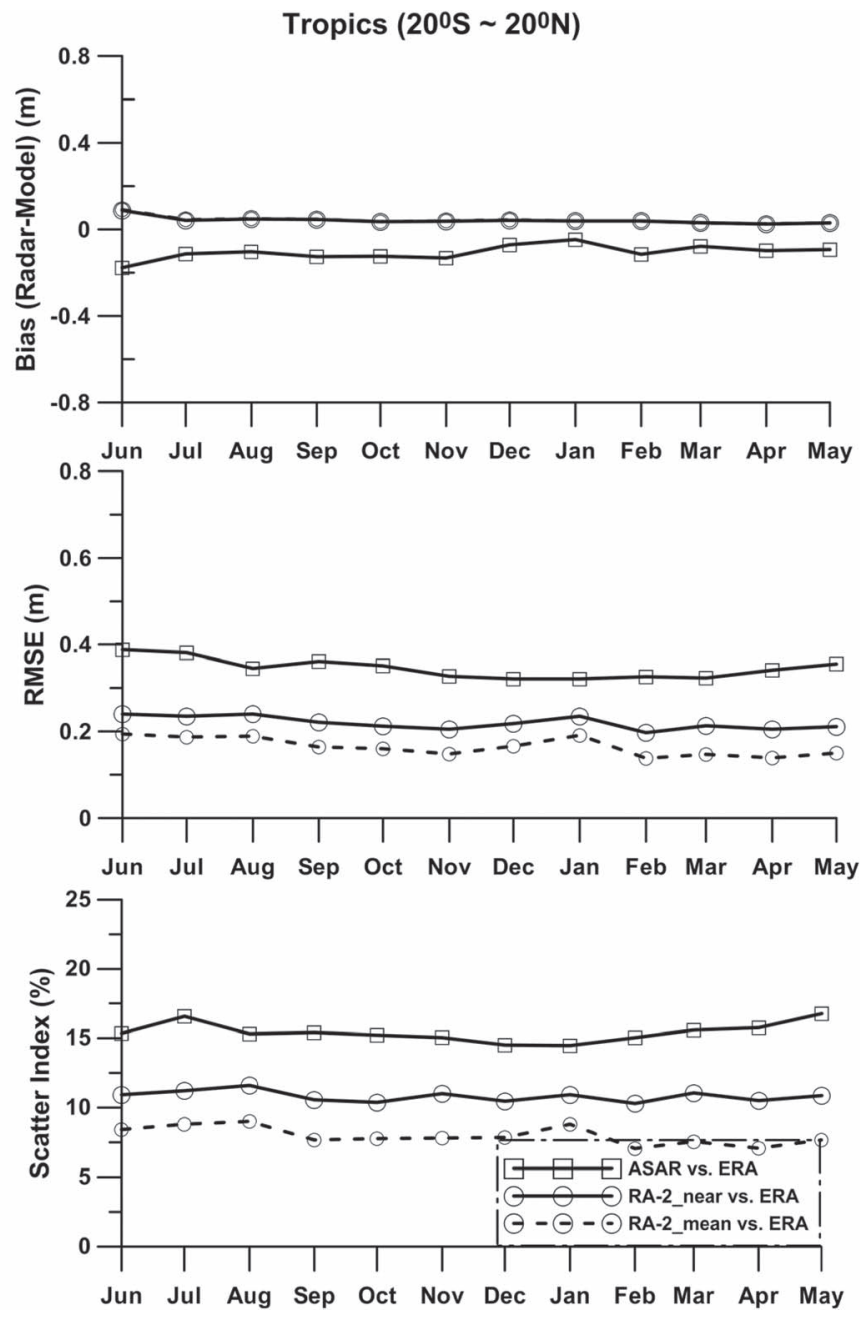

rmse and SI, in global oceans and regional basins, as well as in different seasons. This indicates that the quality of the retrieved SWH from ASAR data by CWAVE_ENV algorithm is comparable to that of RA-2 measurements. Thus, the two independent and simultaneous measurements can be used jointly to evaluate the discrepancies of WAMs in a consistent way.

3) Annual and monthly comparisons show that the two WAMs agree well with both radar measurements of SWH. As it is expected, the reanalysis ERA-Interim WAM shows even better agreement, particularly with RA-2 measurements due to assimilation.

As both the GSM and ERA-Interim WAMs are based on the third-generation WAM, it is considered that differences of the two models compared with satellite measurements are mainly due to the influence of assimilation. In terms of rmse and SI, the difference between ASAR versus GSM and versus ERAInterim models is only $10 \%$. However, it increases significantly to around $44 \%$ (53\%) for the comparison of the nearest (averaged) RA-2 measurements with GSM and ERA-Interim. This indicates that assimilation of RA-2 can improve the accuracy of ERA-Interim wave height by around $44 \%$ relative to the nonassimilated GSM WAM at grids near the RA-2 tracks. 

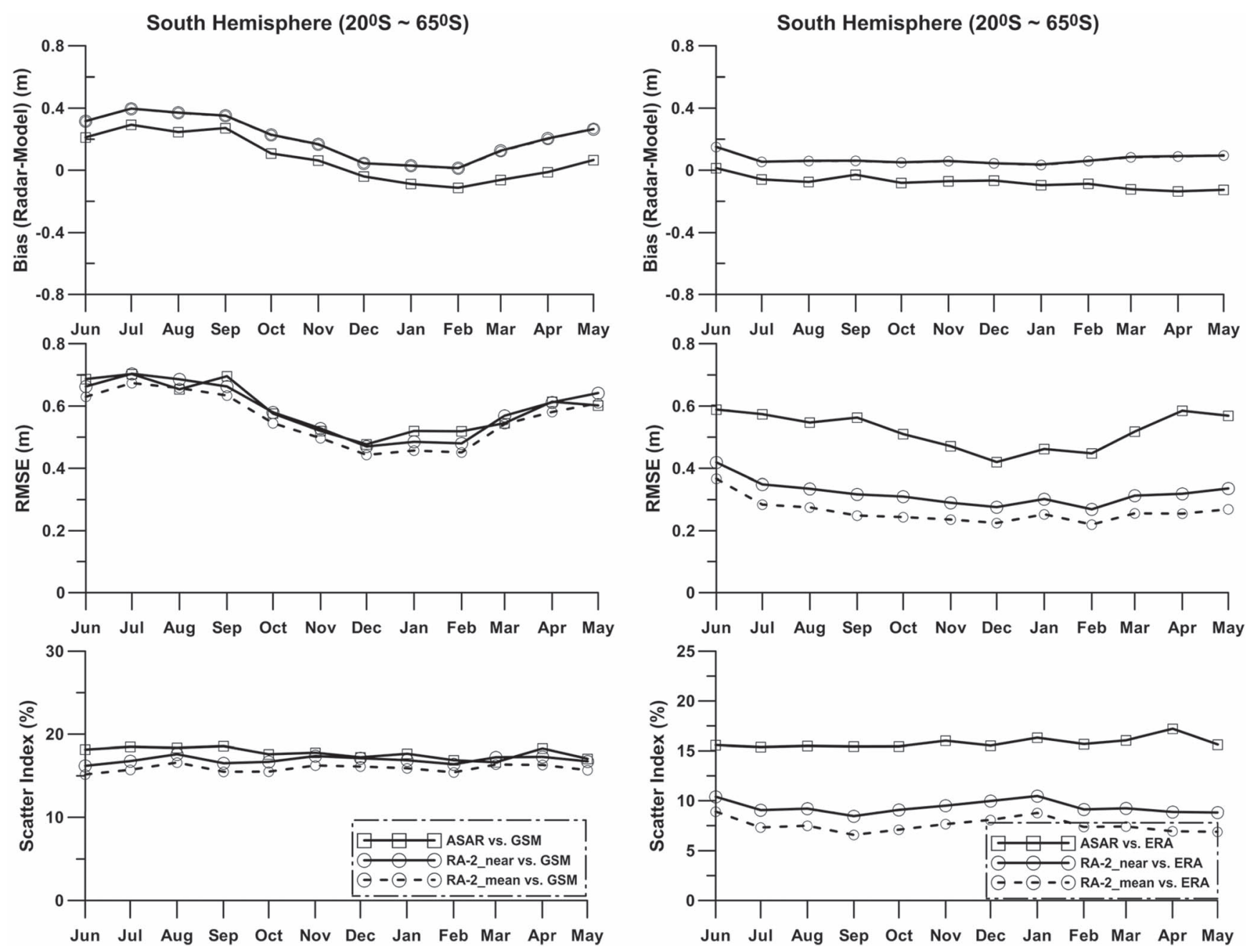

Fig. 9. Same as Fig. 6, but for comparisons in the SH.

The relative difference between ASAR versus ERA-Interim and RA-2 versus ERA-Interim is $37 \%$ in terms of rmse and SI. As the two radar measurements are collocated respectively to model results at grids near their footprints. Therefore, the difference of statistical parameters derived from the two comparisons indicates that the improvement of RA-2 assimilation on the model's accuracy decreases along with the increase of distance. The most plausible reason is that the error correlation function used in the assimilation of ERA-Interim WAM has an exponential expression, which decays rapidly as the distance increases.

The present study is based on a one-year data set; however, the special configuration of ASAR and RA-2 demonstrates its unique advantages for global surface wave measurements. Since slight differences are found in the comparisons of ASAR and RA-2 with the GSM WAM, we are now processing all the ASAR wave mode data acquired between 2002 and 2012 for further retuning of CWAVE_ENV algorithm using buoy collocations. Nevertheless, the SAR and RA are onboard jointly since 1991 when the ERS-1 was launched, and more than one decade data set has been acquired, which can contribute significantly to global wave measurements and assimilation in WAMs.

\section{ACKNOWLEDGMENT}

Advanced Synthetic Aperture Radar wave mode data are kindly provided by the European Space Agency. RA-2 data are accessed from the Center for Satellite Exploitation and Research Web portal.

\section{REFERENCES}

[1] K. Hasselmann, B. Chapron, L. Aouf, F. Ardhuin, F. Collard, G. Engen, S. Hasselmann, P. Heimbach, P. Janssen, H. Johnsen, H. Krogstad, S. Lehner, J.-G. Li, X.-M. Li, W. Rosenthal, and J. Schulz-Stellenfleth, "The ERS SAR wave mode-A breakthrough in global ocean wave observations," in Proc. ERS Missions: 20 Years of Observing the Earth, Y.-L. Desnos, Ed., Noordwijk, NL, 2013, pp. 1-36, ESA SP-1326, ESA/ESTEC.

[2] K. Hasselmann and S. Hasselmann, "On the nonlinear mapping of an ocean wave spectrum into a synthetic aperture radar image spectrum," J. Geophys. Res., vol. 96, no. C6, pp. 10 713-10 729, Jun. 1991.

[3] H. E. Krogstad, "A simple derivation of Hasselmann's nonlinear oceansynthetic aperture radar transforms," J. Geophys. Res., vol. 97, no. C7, pp. 2421-2425, Feb. 1992.

[4] H. Johnsen, G. Engen, F. Collard, V. Kerbaol, and B. Chapron, "Envisat ASAR wave mode products-Quality assessment and algorithm upgrade," in Proc. SEASAR, 2006, ESA SP-613, pp. 1-6.

[5] S. Abdalla, P. A. E. M. Janssen, and J.-R. Bidlot, "Status of global validation of ENVISAT ASAR wave mode products at ECMWF," in Proc. SEASAR Workshop, Frascati, Italy, 2008, ESRIN, ESA SP-656, pp. 1-6. 
[6] J.-G. Li and A. Saulter, "Assessment of the updated Envisat ASAR ocean surface wave spectra with buoy and altimeter data," Remote Sens. Environ., vol. 126, pp. 72-83, Nov. 2012.

[7] L. Aouf, J.-M. Lefèvre, and D. Hauser, "Assimilation of directional wave spectra in the wave model WAM: An impact study from synthetic observations in preparation for the SWIMSAT satellite mission," J. Atmos. Ocean. Technol., vol. 23, no. 3, pp. 448-463, Mar. 2006.

[8] F. Collard, F. Ardhuin, and B. Chapron, "Monitoring and analysis of ocean swell fields from space: New methods for routine observations," J. Geophys. Res., vol. 114, no. C7, pp. C07023-1-C07023-15, Jul. 2009.

[9] F. Ardhuin, E. Rogers, A. Babanin, J.-F. Filipot, R. Magne, A. Roland, A. van der Westhuysen, P. Queffeulou, J.-M. Lefevre, L. Aouf, and F. Collard, "Semiempirical dissipation source functions for ocean waves: Part I, definition, calibration and validation," J. Phys. Oceanogr., vol. 40, no. 9, pp. 1917-1941, Sep. 2010.

[10] J. Schulz-Stellenfleth, T. König, and S. Lehner, "An empirical approach for the retrieval of integral ocean wave parameters from synthetic aperture radar data," J. Geophys. Res., vol. 112, no. C3, pp. C03019-1-C03019-14, Mar. 2007.

[11] X.-M. Li, S. Lehner, and T. Bruns, "Ocean wave integral parameter measurements using ENVISAT ASAR wave mode data," IEEE Trans. Geosci. Remote Sens., vol. 49, no. 1, pp. 155-174, Jan. 2011.

[12] D. J. T. Carter, P. G. Challenor, and M. A. Srokosz, "An assessment of Geosat wave height and wind speed measurements," J. Geophys. Res., vol. 97, no. C7, pp. 11383-11 392, Jul. 1992.

[13] P. G. Challenor and P. D. Cotton, "The joint calibration of altimeter and in situ wave heights," JCOMM, Oostende, Belgium, Tec. Rep. 13, WMO/TD-NO. 1081, 1999.

[14] P. Queffeulou, "Long-term validation of wave height measurements from altimeters," Marine Geod., vol. 27, no. 3/4, pp. 495-510, Jun. 2004.

[15] P. G. Challenor, S. Foale, and D. J. Webb, "Seasonal-changes in the global wave climate measured by the Geosat altimeter," Int. J. Remote Sens., vol. 11 , no. 12 , pp. $2205-2213,1990$

[16] D. K. Woolf, P. G. Challenor, and P. D. Cotton, "Variability and predictability of the North Atlantic wave climate," J. Geophys. Res., vol. 107, no. C10, pp. 9-1-9-14, Oct. 2002.

[17] I. R. Young, S. Zieger, and A. Babanin, "Global trends in wind speed and wave height," Science, vol. 332, no. 6028, pp. 451-455, Apr. 2011.

[18] P. Lionello, H. Günther, and P. A. E. M. Janssen, "Assimilation of altimeter data in a global third-generation model," J. Geophys. Res., vol. 97, no. C9, pp. 14 453-14 474, Sep. 1992.

[19] L.-A. Breivik and M. Reistad, "Assimilation of ERS-1 altimeter wave heights in an operational numerical wave model," Weather Forecast., vol. 9, no. 3, pp. 440-451, Sep. 1994.

[20] S. Abdalla, P. Janssen, and J. Bidlot, "Jason-2 OGDR wind and wave products: Monitoring, validation and assimilation," Marine Geod., vol. 33, no. 1, pp. 239-255, 2010.

[21] R. Romeiser, "Global validation of the wave model WAM over a oneyear period using GEOSAT wave height data," J. Geophys. Res., vol. 98, no. C3, pp. 4713-4726, Mar. 1993.

[22] S. Caires and A. Sterl, "Validation of ocean wind and wave data using triple collocation," J. Geophys. Res., vol. 108, no. C3, pp. 3098-3114, Mar. 2003.

[23] S. Lehner, J. Schulz-Stellenfleth, J. B. Schättler, H. Breit, and J. Horstmann, "Wind and wave measurements using complex ERS-2 wave mode data," IEEE Trans. Geosci. Remote Sens., vol. 38, no. 5, pp. 22462257, Sep. 2000.

[24] J. Schulz-Stellenfleth and S. Lehner, "Measurement of 2-D sea surface elevation fields using complex synthetic aperture radar data," IEEE Trans. Geosci. Remote Sens., vol. 42, no. 6, pp. 1149-1160, Jun. 2004.

[25] P. Queffeulou and D. Croize-Fillon, Global Altimeter SWH Data Set, Ifremer/Cersat Report. [Online]. Available: ftp://ftp.ifremer. $\mathrm{fr} /$ ifremer/cersat/products/swath/altimeters/waves/documentation/ altimeter_wave_merge_9.0.pdf

[26] P. Queffeulou, F. Ardhuin, and J.-M. Lefèvre, "Wave height measurements from altimeters: Validation status and applications," in Proc. OSTST Meeting, San Diego, CA, USA, Oct. 19-21, 2011. [Online]. Available: http://www.aviso.oceanobs.com/fileadmin/documents/OSTST/ 2011/poster/Queffeulou_posterOSTST.pdf

[27] "The WAM model a third generation ocean wave prediction model," J. Phys. Oceanogr, vol. 18, no. 12, pp. 1775-1810, Dec. 1988.
[28] H. Günther, S. Hasselmann, and P. A. E. M. Janssen, "The WAModel cycle 4 (revised version)," DKRZ, Hamburg, Germany, Tech. Rep., 1992

[29] D. P. Dee, S. M. Uppala, A. J. Simmons, P. Berrisford, P. Poli, S. Kobayashi, U. Andrae, M. A. Balmaseda, G. Balsamo, P. Bauer, P. Bechtold, A. C. M. Beljaars, L. van de Berg, N. van de Berg, C. Delsol, R. Dragani, M. Fuentes, A. J. Geer, L. Haimberger, S. B. Healy, H. Hersbach, E. V. Hólm, L. Isaksen, P. Källberg, M. Köhler, M. Matricardi, P. McNally, B. M. Monge-Sanz, J.-J. Morcrette, B.-K. Park, C. Peubey, P. de Rosnay, C. Tavolato, J.-N. Thépaut, and F. Vitart, "The ERA-Interim reanalysis: Configuration and performance of the data assimilation system," Q. J. R. Meteorol. Soc., vol. 137, no. 656, pp. 553-597, Apr. 2011.

[30] P. A. E. M. Janssen, "Progress in ocean wave forecasting," J. Comput. Phys., vol. 227, no. 7, pp. 3572-3594, Mar. 2008.

[31] J.-R. Bidlot, P. A. E. M. Janssen, and S. Abdalla, "Impact of the revised formulation for ocean wave dissipation on the ECMWF operational wave model," ECMWF, Reading, U.K., Tech. Memo. 509, 2007.

[32] IFS documentation-Cy33r1, operational implementation, Part VII: ECMWF wave model, Jun. 2008.

[33] P. Janssen, S. Abdalla, H. Hersbach, and J.-R. Bidlot, "Error estimation of buoy, satellite, model wave height data," J. Atmos. Ocean. Technol., vol. 24, no. 9, pp. 1665-1677, Sep. 2007.

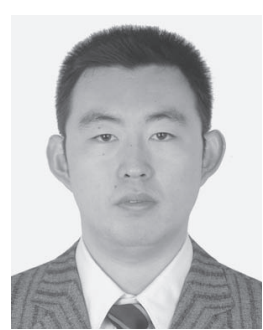

Xiao-Ming $\mathbf{L i}$ received the B.S. degree in electronic and information engineering from $\mathrm{Xi}$ ' an Communication College, People's Liberation Army, Xi'an, China, in 2002, the (equivalent) M.S. degree, with work focusing on satellite ocean remote sensing, from the Ocean University of China, Qingdao, China, in 2006, and the Ph.D. degree in geophysics from the University of Hamburg, Hamburg, Germany, in 2010.

Since 2006, he has been with the Remote Sensing Technology Institute, German Aerospace Center (DLR), Wessling, Germany. His research interests include synthetic aperture radar ocean wave algorithm development, investigation of extremely oceanic weather, and observation of ocean dynamics using spaceborne multisensors.

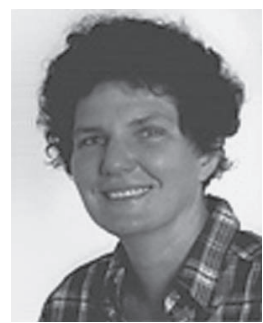

Susanne Lehner (M'01) received the M.Sc. degree in applied mathematics from Brunel University, Uxbridge, U.K., in 1979 and the Ph.D. degree in geophysics from the University of Hamburg, Hamburg, Germany, in 1984.

She was a Research Scientist with Max-Planck Institute for Meteorology, Hamburg. In 1996, she joined the German Remote Sensing Data Center, German Aerospace Center (DLR), Wessling, Germany. She is currently the Head of the SAR oceanography team with the Remote Sensing Technology Institute, DLR, working on the development of algorithms determining marine parameters from synthetic aperture radar.

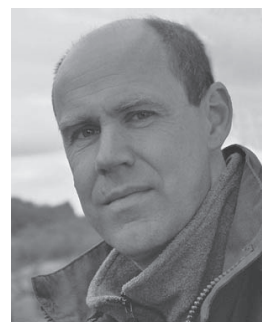

Thomas Bruns received the Diploma degree in meteorology from the University of Hamburg, Hamburg, Germany, in 1981 and the Ph.D. degree from the Max-Planck-Institute for Meteorology, Hamburg, in 1985.

In 1987, he joined Deutscher Wetterdienst (German Weather Service), Hamburg, where he is currently the Head of the Marine Meteorological Consultancy Section. Since 2007, he has been a Member of Joint Technical Commission for Oceanography and Marine Meteorology-Expert Teams on Wind Waves and Coastal Hazards. 